\title{
PERSPECTIVA DA EMANCIPAÇÃO NA AMÉRICA LATINA E DESAFIOS PARA SERVIÇO SOCIAL NO BRASIL E NA COLÔMBIA' ${ }^{1}$
}

\author{
Josefa Batista Lopes \\ Universidade Federal do Maranhão (UFMA)
}

\section{PERSPECTIVA DA EMANCIPAÇÃO NA AMÉRICA LATINA E DESAFIOS PARA O SERVIÇO SOCIAL NO BRASIL E NA COLÔMBIA}

Resumo: O artigo faz indicações de análise histórica sobre desafios do Serviço Social no Brasil e na Colômbia, em relação à perspectiva da emancipação na América Latina, considerando o período histórico aberto com a contrarrevolução burguesa sob o neoliberalismo. Resultado de pesquisas sobre a temática das lutas sociais e o Serviço Social sustentase na análise marxista sobre emancipação como categoria e perspectiva histórica da humanidade, desenvolvendo a hipótese de que: há retrocesso em relação ao movimento de construção da alternativa emancipatória nesse continente, mas também há resistências rearticulando forças e mantendo viva a perspectiva; a vinculação do Serviço Social a essa alternativa, como profissão integrante das estratégias de enfrentamento à questão social, segue as tendências da correlação de forças no movimento social. Conclui, daí, que essa vinculação impõe desafios em todas as dimensões da prática profissional participando, nas particularidades dos dois países, da resistência e sustentação da luta emancipatória em curso na rearticulação de forças dos sujeitos em luta.

Palavras-chave: Emancipação; América Latina, luta de classes, contra revolução burguesa, questão social, Serviço Social.

PERSPECTIVE OF EMANCIPATION IN LATIN AMERICA AND CHALLENGES FOR THE SOCIAL WORK IN BRAZIL AND IN COLOMBIA

Abstract: The article points out the historical analysis about challenges of Social Work in Brazil and Colombia concerning the perspective of the emancipation in Latin America, considering the historical period opened with the counter bourgeois revolution under the neoliberalism. Results of researches on the topic of social struggles and Social Work supports itself on the Marxist analysis of emancipation as a category and historical perspective of humanity, developing the hypothesis that: there is setback in relation to the movement of construction of emancipatory alternative in this continent, but there are also resistance forces regrouping and keeping the expectation alive; the binding of Social Work to this alternative, as a profession that takes part of strategies to deal with social issues, follows the trends of the correlation of forces in the social movement. It concludes that this binding poses challenges in all dimensions of professional practice by participating in the peculiarities of the two countries, of the resistance and support of emancipatory struggle undergoing in the re-articulation of forces of the fighting subjects.

Keywords: Emancipation, Latin America, class struggle, counter bourgeois revolution, social issue, Social Work 


\section{INTRODUÇÃO}

Este artigo apresenta parte dos estudos que envolvem pesquisadores da UFMA, através do Grupo de Estudos, Pesquisa e Debates em Serviço Social e Movimento Social (GSERMS), e pesquisadores da UNICOLMAYOR, no desenvolvimento do projeto de pesquisa Estudo acerca dos Dilemas Éticos e da Postura Política que assumem os Assistentes Sociais na Prática Cotidiana, no âmbito do convênio de colaboração universitária entre a Universidade Colegio Mayor de Cundinamarca (UNICOLMAYOR/ Colômbia) e a Universidade Federal do Maranhão (UFMA/Brasil). Resulta da continuidade dos estudos e análises feitas no texto Ética e Desenvolvimento no Contexto da Crise do Capital: apontamentos para um estudo crítico (LOPES, 2012). Nesse sentido, a emancipação, o cerne da ética, como perspectiva histórica da humanidade e ético-política dos homens, conforme pensada no trabalho anterior referido, é agora o eixo da análise; considerada em sua historicidade no continente latino-americano no período histórico aberto na década de 90 do século XX com a contrarrevolução burguesa. É quando avança e se consolida no continente o movimento mundial de administração da crise do capital ${ }^{3}$ que golpeou o capitalismo na primeira metade da década de 70 daquele século; um movimento que operou uma profunda transformação econômica e ideológica. $\mathrm{Na}$ economia, com a reestruturação das relações de produção e de trabalho hegemonizada pelo capital financeiro ${ }^{4}$, o capital rentista; e, no campo ideológico, o neoliberalismo ${ }^{5}$ orientou a reforma dos Estados nacionais que deveriam sustentar e responder as demandas da nova fase da economia, ao mesmo tempo em que forjava a cultura que the corresponde, com reorientação em todas as instâncias de sua formação, destacadamente a educação. Garantiria, assim, a unidade entre economia e política ${ }^{6}$. Um movimento cuja adesão na América Latina, segundo Boron (2004, p.9), ocorre em três momentos: o primeiro no final dos anos 70 e começo dos 80 do século XX, através de Bolívia, Chile e México; o segundo a partir do final dos anos 80 com Costa Rica, Equador, Jamaica, Trinidad e Tobago e Uruguai; a terceira onda levou Argentina, Brasil, Colômbia, El Salvador, Guatemala, Guianas e Honduras, países que Boron considera reformadores tardios.

Trata-se, efetivamente, de uma contra revolução que, com apoio militante da Igreja Católica ${ }^{7}$, golpeou todos os movimentos de tendência socialista e comunista no mundo. A partir da União das Repúblicas Socialistas Soviéticas (URSS), a maior referência histórica desses movimentos, independentemente de todas as críticas que se possa e se deva fazer; mas golpeou também o próprio liberalismo ${ }^{8}$. E, por conseguinte, metamorfoseou as condições objetivas e subjetivas das lutas sociais e de classes; impôs derrota e retrocesso ao movimento de construção da alternativa emancipatória (ABREU e LOPES, 2004) no continente, com profunda desvantagem para seus sujeitos históricos, na correlação de forças nas lutas contra a exploração, a dominação e a humilhação: pela emancipação entendendo que, segundo Marx (2012, p. 71)

Só quando o homem individual real
retoma em si o cidadão abstrato e,
como homem individual - na sua vida
empírica, no seu trabalho individual, nas
suas relações individuais -, se tornou
ser genérico; só quando o homem
reconheceu e organizou as suas 'forces
propres' como forças sociais, e, portanto,
não separa mais de si a força social na
figura da força política - [é] só então
[que] está consumada a emancipação
humana

No processo de adesão e de consolidação do neoliberalismo na América Latina, Brasil e Colômbia assumem particularidades que efetivamente incidem sobre o Serviço Social como profissão integrante das estratégias de enfrentamento à questão social.

\section{O ESGOTAMENTO DE UM CICLO DE LUTAS} EMANCIPATÓRIAS: o Serviço Social e as atuais condições de rearticulação de forças dos sujeitos da luta emancipatória

A atual fase do capitalismo marca, de fato, o esgotamento do ciclo de lutas emancipatórias na América Latina aberto no final da década de 50 do século $X X$ tendo como marco histórico a vitória da Revolução Cubana em 1959. Ela marcou todo o continente com maior ou menor intensidade nos diferentes países; penetrou profundamente os movimentos dos trabalhadores nas cidades e no campo, a cultura de massas, os intelectuais, as universidades, a Igreja Católica, difundindo a ideologia emancipatória e a perspectiva de uma sociedade alternativa ao capitalismo. As classes dominantes do continente, aliadas à burguesia dos países imperialistas (FLORESTAN, 1973, p.11) atuaram para impedir o avanço desses movimentos com todos os meios de controle, dos quais o mais efetivo foram as ditaduras militares ${ }^{9}$ que eram instauradas com a bandeira da modernização, certamente a modernização conservadora. Segmentos expressivos de assistentes sociais, sujeitos profissionais do Serviço Social, à época de constituição recente como profissão com formação acadêmica $^{10}$, não demoraram a se envolver no movimento emancipatório, mobilizados em todo o continente pelo Movimento de Reconceituação ${ }^{11}$; pela natureza da profissão, vinculada à assistência e ao assistencialismo em nada emancipador ${ }^{12}$, esses profissionais envolveram-se e envolveram a profissão, em consequência, nas "[...] malhas da modernização conservadora e do projeto alternativo 
de sociedade." em marcha (LOPES, 1998). Ou seja, no exercício profissional eles se vinculam, organicamente, como trabalhadores assalariados, a instâncias de controle das lutas emancipatórias e, também aí se vinculam a essas lutas; tomaram consciência do caráter contraditório da profissão e de sua condição de sujeito de luta, como trabalhadores.

$\mathrm{Na}$ atual fase, as condições objetivas e subjetivas das lutas sociais foram profundamente metamorfoseadas. Foram, portanto, metamorfoseadas também as condições objetivas e subjetivas da organização dessas lutas com ampla desvantagem para os sujeitos das lutas emancipatórias. Em particular para os trabalhadores que perderam grande parte de suas conquistas históricas, tragadas pela contrarrevolução burguesa no novo regime de acumulação flexível (HARVEY, 1992, p.119) ${ }^{13}$ que, filiado à complexa dinâmica do capital portador de juros (CHESNAIS, 2005, p. 35), flexibilizou a organização da produção e do trabalho, mediante a reestruturação da organização orientada pelo sistema fordista e fordista-keynesiano.

Segundo Harvey (1992, p.125) o sistema fordista, que tem em 1914 a data simbólica de seu início, formou

[...] a base de um longo período de expansão do segundo pós-guerra que se manteve mais ou menos intacto até 1973. [...] O fordismo se aliou ao keynesianismo e o capitalismo se dedicou a um surto de expansões internacionalistas de alcance mundial que atraiu para sua rede inúmeras nações descolononizadas. [...] O equilíbrio de poder, tenso, mas mesmo assim firme, que prevalecia entre o trabalho organizado, o grande capital corporativo e a nação-Estado, e que formou a base de poder da expansão do pós-guerra não foi alcançado por acaso - resultou de anos de luta.

Ao promover a reestruturação da organização da produção e do trabalho, o movimento de flexibilização forjou também a reação conservadora no modo de pensar e de agir, a cultura e a ideologia da chamada pós-modernidade; metamorfoseou as relações de exploração, dominação e humilhação com a crescente terceirização da produção, a precarização do trabalho e a fragmentação da classe trabalhadora (ANTUNES, 1999) basilares no arrefecimento do movimento operário e na fragmentação das lutas sociais. As instituições clássicas, tradicionais do movimento operário, os sindicatos e partidos políticos, que avançavam na direção da organização dos trabalhadores como classe, desde o século XIX, foram profundamente confrontadas: os sindicatos em grande parte esvaziados; e partidos políticos de esquerda foram metamorfoseados e afastaram-se da perspectiva emancipatória, tornando-se partidos da ordem, como o Partido dos Trabalhadores (PT) no Brasil, a partir da eleição de Luís Inácio Lula da Silva para o governo da República do Brasil, em 2002 e posse em 2003.

\section{SERVIÇO SOCIAL NA TEIA DAS CONTRADIÇÕES DO DESENVOLVIMENTO HUMANO E DAS ESTRATÉGIAS DE ENFRENTAMENTO DA QUESTÃO SOCIAL:} entre o reino das necessidades e o reino da liberdade

Reafirmo aqui a concepção de que a questão social (LOPES, 2008) se funda nas necessidades ${ }^{14}$ humanas não satisfeitas em razão das profundas desigualdades sociais inerentes às sociedades de classes que ao longo da história dessas sociedades travam uma luta incessante, a luta de classes na qual a questão social é sintetizada. Em consequência, outra premissa se impõe: não há solução para a questão social no contexto do capitalismo; o que há são mecanismos e formas de seu enfrentamento, através de políticas que colocam o Estado no centro da luta de classes, respondendo, fundamentalmente, aos interesses das classes dominantes, ainda que, contraditoriamente, procurando responder demandas das classes subalternas, conforme demonstrado em uma vasta literatura sobre o Estado e suas contradições ${ }^{15}$. Coloca-se aí um dos mais importantes desafios para o Serviço Social, como expressão da práxis ${ }^{16}$. Segundo Marx (1974, p. 942)

De fato o reino da liberdade começa onde o trabalho deixa de ser determinado por necessidade e por utilidade exteriormente imposta; por natureza, situa-se além da esfera da produção material propriamente dita. $\mathrm{O}$ selvagem tem de lutar com a natureza para satisfazer as necessidades, para manter e reproduzir a vida; e o mesmo tem de fazer o civilizado, sejam quais forem a forma de sociedade e o modo de produção. Acresce, desenvolvendose, o reino do imprescindível. É que aumentam as necessidades, mas, ao mesmo tempo, ampliam-se as forças produtivas para satisfazê-las. Aliberdade nesse domínio só pode consistir nisto: o homem social, os produtores associados regulam racionalmente o intercâmbio com a natureza, controlam-no coletivamente, sem deixar que ele seja a força cega que os domina; efetuamno com o menor dispêndio de energias e nas condições mais adequadas e mais condignas com a natureza humana. Mas esse esforço situar-se-á sempre no reino da necessidade. Além dele começa o desenvolvimento das forças 
humanas como um fim em si mesmo, o reino genuíno da liberdade, o qual só pode florescer tendo por base o reino da necessidade. E a condição desse desenvolvimento humano é a redução da jornada de trabalho.

Nos países de capitalismo dependente, como nos países da América Latina e da África, as condições de extrema pobreza ou de pobreza, tendencialmente com altos índices de desemprego, as necessidades primárias de subsistência se impõem; e as respostas são prioritariamente através de políticas assistenciais que representam formas compensatórias que sequer abrem espaço às necessidades radicais que nascem do trabalho. Estas necessidades, segundo Agnes Heller (1978:106) "são parte constitutiva orgânica do 'corpo social' do capitalismo, mas de satisfação impossível dentro desta sociedade e que, precisamente por isto, motivam a práxis que transcende a sociedade determinada".

\section{CONCLUSÃO}

O esgotamento do ciclo de lutas emancipatórias aberto na América Latina no final da década de 50 do século $X X$ não significa o fim da perspectiva emancipatória no continente e no mundo na atual fase do capitalismo. Com a fragmentação da classe trabalhadora e todas as consequências acima referidas, a perspectiva de solução da questão social apresenta uma complexidade maior do que parecia no final do século $X I X$ e até metade do século $X X$, quando ocorreram algumas revoluções vitoriosas ao redor do mundo. Tem-se um quadro em que, a frase de Rosa Luxemburgo Socialismo ou barbárie, segundo Mészáros (2003),

"[...] adquiriu uma urgência dramática. Não existem rotas conciliatórias de fuga [...] somente uma alternativa radical ao modo estabelecido de controle da reprodução do metabolismo social pode oferecer uma saída da crise estrutural do capital".

Em cada país no continente, na síntese de suas construções históricas, o Serviço Social tem especificidades em suas experiências nas malhas contraditórias particulares de cada Estado nação; mas sob as mesmas determinações históricas do desenvolvimento capitalista dependente participando das estratégias de enfrentamento da questão social, em países que nem experimentaram o Estado de Bem Estar, como na Europa e nos Estados Unidos. 0 fim do ciclo marcado por derrotas (PETRAS, 1995).

Nas atuais condições, desfavoráveis à perspectiva da emancipação, sua sustentação é tarefa da resistência de seus sujeitos históricos para os quais se trata de uma necessidade histórica: os trabalhadores do campo e da cidade, os explorados, dominados e humilhados em todos os espaços e condições de vida. Importantes movimentos de resistência e rearticulação de forças dos sujeitos da luta emancipatória estão em curso no continente, agora com mais clareza na luta contra o capitalismo e não com foco no liberalismo em si, como ocorreu no início da adesão do continente às reformas. Neste sentido, cabe apoiar e acompanhar com atenção os desdobramentos da reestruturação da experiência socialista de Cuba, avançando para uma economia mista; e as experiências de governos que no continente se reivindicam de esquerda como: Bolívia, Equador e Venezuela. Particularmente vale acompanhar a articulação desses países, reunidos com Cuba e Nicarágua na Aliança Bolivariana para os Povos da Nossa América - Tratado de Comércio dos Povos, a antiga Alternativa Bolivariana para as Américas (ALBA).

É uma perspectiva de esperança. Em 1973, Salvador Allende, em seu último discurso ao povo chileno, após o qual foi atacado pelo golpe militar sob as ordens de Augusto Pinochet, no palácio presidencial, lançou esta mensagem:

\begin{abstract}
Mucho más temprano que tarde, de nuevo se abrirán las grandes alamedas por donde pase el hombre libre para construir una sociedad mejor. (ALLENDE, 1973).
\end{abstract}

\section{REFERÊNCIAS}

ABREU, Marina Maciel; LOPES, Josefa. Asolidariedade e o projeto histórico de emanciapação humana: questões e perspectivas no Brasil. In: CONFERÊNCIA LA OBRA DE CARLOS MARX Y LOS DESAFÍOS DEL SIGLO XXI, 2., 2004, Hayana. Anais... Havana: [s. n.], 2004.

ALLENDE, Salvador. Último Discurso. [S. I.: s. n.], 1973. Disponível em: <http://vozes-militantes. blogspot.com.br/2010/02/o-ultimo-discurso-desalvador-allende.html>. Acesso em: 27 maio 2013.

ANTUNES, Ricardo. Os Sentidos do Trabalho. São Paulo: Boitempo,1999

ANDERSON, Perry. O balanço do neoliberalismo. In: SADER, Emir; GENTILI, Pablo (Orgs.). Pós neoliberalismo: as políticas Sociais e o Estado Democrático. Rio de Janeiro: Paz e Terra, 1995.

BORON, Atílio. Las reformas del Estado em América Latina: sus negativas consequências sobre la inclusión social y la participación democrática. Temporalis, Porto Alegre, ano 4, n. 7, 2004.

CHESNAIS, François (Org.) A Finança mundializada: raízes sociais e políticas, configuração, conseqüências. São Paulo: Boitempo, 2005. 
et al .Uma nova fase do capitalismo? São

Paulo: Cemarx/Xamã, 2003.

CORNELY, Seno Antonio. História da Organização Político-acadêmica do Serviço Social na América Latina. Temporalis, Porto Alegre, ano 4, n. 7, 2004.

FLORESTAN, Fernandes. Padrões de Dominação Externa na América Latina. In: Capitalismo Dependente e Classes Sociais na América Latina. Rio de Janeiro: Zahar Editores, 1973.

GRAMSCI, Antonio. Cadernos do Cárcere: breves notas sobre a política de Maquiavel. Rio de Janeiro: Civilização Brasileira, 2000. v. 3, cad. 13.

HARVEY, David. A Condição Pós-moderna. São Paulo: Edições Loyola, 1992.

HELLER, Agnes. La teoria de las necessidades en Marx. [S. I.: s. n.], 1978.

LOPES, Josefa Batista. O Serviço Social na América Latina: nas malhas da modernização conservadora e do projeto alternativo de sociedade. 1998. Tese (Doutorado em Serviço Social) Programa de Pós-Graduação em Serviço Social, Pontifícia Católica de São Paulo, São Paulo, 1998.

Ética e Desenvolvimento no Contexto da Crise do Capital: apontamentos para um estudo crítico. Revista de Políticas Públicas, São Luís, v. 14, n. especial, 2012.

A luta de classes como elemento constitutivo e motor da solução da questão social. In: CONFERÊNCIA MUNDIAL DE ASSISTENTES SOCIAIS, 19., 2008, Salvador. Anais... Salvador: FITS/CFESS, 2008.

MANRIQUE, Manuel Castro. História do Serviço Social na América Latina. Lima: CELATS; São Paulo: CORTZ, 1984.

MARX, K. O Capital: crítica da economia política. Rio de Janeiro: Civilização Brasileira, 1974. Volume $6 / 3$ - O processo global de produção capitalista.

Emancipação política e emancipação humana. In: NETTO, José Paulo (Org.). O leitor de MARX. Rio de Janeiro: [s. n.], 2012.

MÉSZÁROS, István. A taxa de utilização decrescente e o Estado Capitalista: Administração da crise e auto-reprodução destrutiva do capital. In:

Para além do capital. São Paulo: Boitempo, 2002.

PETRAS, James. Ensaios contra a ordem. São Paulo: Scritta, 1995.

\section{NOTAS}

1 Trabalho exposto na mesa temática coordenada Serviço Social como uma expressão da práxis na crise contemporânea do capitalismo: fundamentos e tendências no Brasil e na Colômbia apresentada na VI Jornada Internacional de Políticas Públicas - VI JOINPP realizada no período de 20 a 23 de agosto de 2013

2 Ver Mészáros (2002, p. 695). Segundo o filósofo "Talvez o aspecto mais significativo da bem sucedida redefinição, por parte do capital, da linha de menor resistência de maior alcance (e, com isso, o deslocamento temporário de suas contradições) seja, se comparado a um passado não muito distante, o modo radicalmente novo de administrar crises. [...] sob as novas condições - desde que os seus prérequisitos materiais e político/ideológicos possam ser objetivamente reproduzidos - não precisam assumir, de maneira alguma, a forma pela qual a contradição entre produção e troca 'descarrega a si mesma em grandes tempestades'. "

3 Para um avanço no estudo e debate sobre a hegemonia financeira na atual fase do capitalismo ver, entre outros, os textos da coletânea organizada por François Chesnais (2005) A Finança mundializada: raízes sociais e políticas, configuração, conseqüências, publicada no Brasil pela Boitempo. E também outra coletânea, Uma nova fase do capitalismo? (CHESNAIS, et al. 2003), obra na qual me apoio, particularmente, no debate sobre a atual fase do capitalismo, ou seja a tese de que as transformações ocorridas no desenvolvimento do capitalismo, a partir da década de 70 do século $X X$, constituíram uma nova fase do capitalismo.

4 Esse processo é datado pelos estudiosos, a partir de sua forte manifestação, através da vitória do governo conservador de Margareth Thatcher, na Inglaterra, em 1979, logo seguida pelas vitórias de Ronald Reagan nos Estados Unidos, em 1980 e Helmout Koll na Alemanha, em 1982. Mas efetivamente iniciado, segundo Anderson (1995, p.11) "[...] logo depois da II Guerra Mundial na região da Europa e da América do Norte onde imperava o capitalismo. Foi uma reação teórica e política contra o Estado intervencionista e de bem-estar." Na América Latina, o Chile, sob a ditadura de Pinochet, segundo Anderson (1995, p. 19) "[...] tem a honra de ter sido o verdadeiro pioneiro do ciclo neoliberal da história contemporânea [...] é de se notar que a experiência chilena dos anos 70 interessou muitíssimo a certos conselheiros britânicos importantes para Thatcher, na Inglaterra."

5 Gramsci (2000, p26) dá uma importante contribuição ao amplo debate que o pensamento marxista dedica à questão da unidade economia e política, da estrutura e a superestrutura. Ver, em especial o Caderno 13.

6 Karol Wojtyla, o papa João Paulo II, primeiro papa polonês envolveu-se diretamente no movimento anticomunista e nos acordos que resultaram nas reformas que culminaram a plena derrocada da União das Repúblicas Socialistas Soviéticas - URSS, com a Perestroika e a Glasnost, de Mikhail Gorbachev, pondo fim à Guerra Fria e criando as condições de avanço do capitalismo nos países do Leste Europeu. 
7 Desenvolvi esse tema no artigo "Pós-modernidade: superação da modernidade ou reação conservadora?" (LOPES, 1993).

8 Países: República Dominicana (1889-1899, $1930-$ 1961); Colômbia (1953-1957); Brasil (1964-1985); Argentina (1976-1983); Bolívia (1971-1985); Chile (1973-1989); El Salvador (1931-1979); Equador (1972-1979); Guatemala (1970 - 1985); Haiti (19571990); Honduras (1963-1974); México (1853-1855, 1876-1910); Nicarágua (1967-1979); Panamá (19681989); Paraguai (1954-1989); Peru (1968-1980); Venezuela (1908-1935, 1952-1958); Uruguai (19731984); Suriname (1980-1988).

9 A primeira Escola de Serviço Social foi fundada no Chile, em 1925, seguida pelo Brasil, em 1936 e Peru, em 1937 (MANRIQUE,1984).

101965 é considerada a data de deflagração organizada do movimento durante o I Seminário de Serviço Social face às mudanças sociais na América Latina, que reuniu em Porto Alegre, Brasil assistentes sociais da Argentina, do Brasil da Bolívia, do Paraguai e do Uruguai, especialmente vinculadas à academia (CORNELY, 2004, p 53)

11 O assistencialismo é, aliás, o núcleo central da crítica levantada no movimento de reconceituação em torno da prática profissional na perspectiva de sua superação.

12 Harvey (1992, p.119), cauteloso diante do "perigo de confundir as mudanças transitórias e efêmeras com as transformações de natureza mais fundamental da vida político-econômica", entende que: "os contrastes entre as práticas político-econômicas da atualidade e as do período de expansão do pós-guerra são suficientemente significativos para tornar a hipótese de uma passagem do fordismo para o que poderia ser chamado regime de acumulação 'flexível' uma reveladora maneira de caracterizar a história recente".

13 Dada a centralidade da categoria das necessidades para esta análise e que a categoria não será tratada neste texto é importante ressaltar que trabalho aqui com a análise que faz Agnes Heller (1978) sobre a Teoria das necessidades em Marx.

14 Nessa direção da análise destaco a contribuição de Gramsci (2000) por sua influência nos estudos do Serviço Social sobre a temática no continente.

15 É o tema central da mesa coordenada. Poderá ser visto no texto elaborado por Marina Maciel Abreu e Franci Gomes Cardoso.

\section{Josefa Batista Lopes}

Assistente Social

Doutora em Serviço Social pela Pontifícia Universidade Católica de São Paulo (PUC/SP)

Professora Aposentada da Universidade Federal do Maranhão (UFMA)

Professora do Programa de Pós-Graduação em Políticas Públicas (UFMA)

E-mail: josefablopes@uol.com.br

\section{Universidade Federal do Maranhão - UFMA}

Cidade Universitária do Bacanga

Avenida dos Portugueses, 1966- Bacanga

85.085-580- São Luís-Ma 